\title{
An almond-enriched diet increases plasma $\alpha$-tocopherol and improves vascular function but does not affect oxidative stress markers or lipid levels.
}

Choudhury K. Clark J. and Griffiths H.R.

Life \& Health Sciences

Aston University

Aston Triangle

Birmingham B4 7ET

UK

Corresponding author and address for correspondence

Professor Helen R Griffiths

Life and Health Sciences

Aston University

Aston Triangle

Birmingham B4 7ET

UK

Tel: +44 (0) 1212043950

Fax: +44(0) 1212044075

Email- h.r.griffiths@aston.ac.uk

Running title; Dietary almonds improve plasma $\alpha$-tocopherol and vascular function Keywords; $\alpha$-tocopherol; blood pressure; monounsaturated fatty acid; protein carbonyl; nitric oxide; ageing; almond. 


\section{Abstract}

Vascular dysfunction is one of the major causes of cardiovascular (CV) mortality and increases with age. Epidemiological studies suggest that Mediterranean diets and high nut consumption reduce $\mathrm{CV}$ disease risk and mortality while increasing plasma $\alpha$-tocopherol. Therefore, we have investigated whether almond supplementation can improve oxidative stress markers and CV risk factors over 4 weeks in young and middle-aged men.

Healthy middle-aged men (56+5.8years), healthy young men (22.1+2.9years) and young men with two or more CV risk factors (27.3+5years) consumed $50 \mathrm{~g}$ almond /day for 4 weeks. A control group maintained habitual diets over the same period.

Plasma $\alpha$-tocopherol/cholesterol ratios were not different between groups at baseline and were significantly elevated by almond intervention with $50 \mathrm{~g}$ almond/day for four weeks $(p<0.05)$. Plasma protein oxidation and nitrite levels were not different between groups whereas total, HDL and LDL cholesterols and triglycerides were significantly higher in healthy middle-aged and young men with $\mathrm{CV}$ risk factors but were not affected by almond intake. In the almond consuming groups, flow mediated dilatation (FMD) was improved and diastolic blood pressure was reduced significantly after 4 weeks, but systolic blood pressure was only reduced in healthy men.

In conclusion, a short-term almond-enriched diet can increase plasma $\alpha$-tocopherol and improve vascular function in asymptomatic healthy mean men aged between 20 and 70 without effect on plasma lipids or markers of oxidative stress. 


\section{Introduction}

Ageing is considered the major non-modifiable risk factor for cardiovascular disease (CVD)

[1]. Independent risk factors for CVD include increased blood lipid concentrations (LDL, triacylglycerols and free fatty acids), blood pressure (BP), haemostatic factors, inflammatory markers, oxidative stress markers and endothelial dysfunction [2] and each of these risk factors is influenced by age [3]. For example, between $40-69$ years, each $20 \mathrm{mmHg}$ rise in systolic BP or $10 \mathrm{mmHg}$ rise in diastolic BP associates with a two-fold increase in death rate from vascular disease [3]. Elevations in BP can be attributed at least in part to arterial stiffening, an irreversible process that progresses through all blood vessels during ageing. In healthy subjects without confounding risk factors or significant systemic inflammation, a more oxidized plasma cysteine/cystine environment correlates with increased arterial stiffness [4]. In aorta from old mice with increased total, adventitial and medial advanced glycation endproducts (AGEs), vessels were de-stiffened by sodium nitrite therapy secondary to decreasing oxidative stress, indicating that it is possible to improve impaired vascular reactivity of ageing, an important risk factor for CVD [5].

Elevated plasma lipids are important independent risk factors for CVD and typically, total cholesterol and the LDL:HDL ratio increase with ageing. For over 40 years, it has been known that Mediterranean populations have a low prevalence of coronary heart disease and low plasma cholesterol levels despite high total fat consumption; however, saturated fatty acid intake is typically low in these populations and the merits of a Mediterranean diet with high monounsaturated (MUFA), polyunsaturated fatty acids (PUFA) and antioxidant micronutrients were propounded [6]. A number of randomised controlled trials were developed to investigate vitamin E and/or $\alpha$-tocopherol on cardiovascular outcomes with the most recent Cochrane review finding no evidence to support antioxidant supplements 
for primary or secondary prevention of CVD [7]. The epidemiological evidence for disease prevention by dietary antioxidants is now considered within a hormesis model whereby they exert a paradoxical oxidative activation of the adaptive response transcription factors e.g. Nrf2 and processes such as autophagy which regulate prevention, repair and removal of molecular damage $[8,9]$. In support of this, $\alpha$-tocopherol has been shown to promote autophagy in rat liver and activation of autophagy in the vasculature by spermidine reverses arterial ageing[10,11]. The protective effects of the Mediterranean diet most likely reflects the combined effects of many nutrients in any given diet or foodstuff working in synergy. Almonds are major dietary sources of $\alpha$-tocopherol and MUFA and frequent nut consumption reduces the risk of fatal coronary heart disease, non-fatal myocardial infarction [12], and sudden cardiac death [13]. Additional nutrients in almonds that associate with positive cardiovascular outcomes include antioxidant flavanoids and arginine, the rate limiting precursor in the biosynthesis of the vasodilatory molecule, nitric oxide. The exact nutrient composition of almonds varies with cultivar [14] and the beneficial effects of almonds may be due to a combination of nutrients.

A meta-analysis of dietary almond interventions concluded that the present randomized trials do not support almond ingestion for any lipid modifying effects [15]. However, dietary intervention with almonds has improved markers of insulin sensitivity in adults with prediabetes [16]. Independently, consumption of almonds was shown to influence a few but not all markers of inflammation and haemostasis in a dose-independent manner [17]. Further study is needed to inform the mechanisms of and populations who can benefit from dietary interventions with almonds to reduce CV risk.

Therefore we have investigated the potential for dietary intervention with almonds to increase plasma $\alpha$-tocopherol concentration and reduce oxidative biomarkers, as a 
mechanism for reducing risk factors for CVD (reducing BP, improving impaired vascular reactivity of ageing and decreasing lipids) in asymptomatic healthy young and older adults. 


\section{METHODS}

\section{Subjects}

Male participants only were investigated in the present study as the effect of age on CVD risk in women is confounded by oestrogen levels and age of menopause[18]. From a pilot study which showed effects from $50 \mathrm{~g} / \mathrm{d}$ but not $25 \mathrm{~g}$ almonds/d over 4 weeks, we calculated that a sample size of 15 subjects per group was needed to power the study to detect a $5 \%$ difference in $\mathrm{BP}$, lipids and a $10 \%$ change in flow mediated dilatation after intervention with $80 \%$ power and $95 \%$ probability. Therefore, 60 males who were resident in the United Kingdom were recruited to the study and were grouped by age and health status.

Participants were excluded if they were taking prescribed medication for lipid management, diabetes or if they were smokers, regular users of antioxidant supplements and taking antiinflammatory drugs. Ethical approval for the study was provided by Aston University Ethics committee.

Group 1 subjects; "healthy middle-aged" men, comprised of 20 men aged over 55 years with fasting $(12 \mathrm{~h}$ ) plasma triacylglycerol $<220 \mathrm{mg} / \mathrm{dL}$, or total cholesterol $<250 \mathrm{mg} / \mathrm{dL}$. One in four of subjects recruited to this group were assigned to the habitual diet group, Group 4. Group 2 subjects; "healthy young" men, comprised of 20 men aged between 18 and 35 years of age, with fasting ( $12 \mathrm{~h}$ ) plasma triacylglycerol $<220 \mathrm{mg} / \mathrm{dL}$, or total cholesterol < $250 \mathrm{mg} / \mathrm{dL}$, blood and body mass index (BMI) between 17 and 22.5. One in four of subjects recruited were assigned to the habitual diet group, Group 4.

Group 3 subjects; "young, at risk" for cardiovascular disease men, comprised of 20 men aged between 18 and 35 years of age, with at least one risk factor (lipids, BP, BMI) above the normal range. One in four of subjects recruited were assigned to the habitual diet group, Group 4. 
Group 4 subjects; (control) comprised 15 male subjects $>18$ years of age. Five subjects were randomly assigned to this group from each of the three groups above.

\section{Experimental design}

A four week almond supplementation design was used because plasma lipid and lipoprotein concentrations stabilize within 2-3 weeks of altering diet [19]. Subjects were recruited throughout the year to avoid seasonal dietary effects in nutrient intake. Subjects consumed either their habitual diet (group 4) or were asked to substitute any daily snack for 2 bags of almonds $(50 \mathrm{~g})$ and otherwise to eat to satiety (groups 1-3). Almonds provided $14 \mathrm{mg} \alpha-$ tocopherol per 50g and the monounsaturated fatty acid, oleic acid was the major fatty acid constituent, exceeding $50 \%$ of mass.

Compliance with the intervention diet was assessed with 3-day food diaries, including a weekend day and bag return. Compliance exceeded 92\%. Estimated dietary intakes were calculated with DietPlan6 software programme (Forestfield Software, Horsham).

Six participants assigned to the control group withdrew after 4 weeks. All other subjects continued throughout the study. Procedures involving human subjects were approved by the Aston University ethical committee.

Fasting blood samples (baseline and after 4 weeks almonds) were collected into EDTA and centrifuged at $498 \times g$ (Heraeus instruments labofuge 400R) for 10mins within 2 hours of collection. The plasma was separated and aliquoted and stored at $-80^{\circ} \mathrm{C}$ until required for analysis. Aliquots were not freeze-thawed.

\section{Plasma lipid determinations}

Triacylglycerol and cholesterol concentrations were measured enzymatically with CHOD-PAP kits from Randox, Ireland. Each assay included appropriate standards and calibrators. Interassay coefficients of variation (CV)s were $3.5 \%$ for triacylglycerol and $5.1 \%$ for 
cholesterol analysis. HDL was separated from the plasma by precipitation with dextran sulfate and magnesium chloride and cholesterol was analysed by CHOD-PAP. The CV for HDL cholesterol analysis was $2.5 \%$.

\section{Blood pressure, BMI and flow mediated dilatation (FMD)}

BP measurements were taken twice from volunteers after sitting for 5 minutes with the brachial artery level with the heart, using a manual sphygmomanometer.

Blood flow measurements were obtained by venous occlusion plethysmography. The venous flow in the forearm was stopped using a sphygmomanometer for $10 \mathrm{sec}$ at $40 \mathrm{mmHg}$ whilst still allowing arterial flow. After releasing the pressure, the rate at which venous flow returned to normal was calculated. The $\mathrm{CV}$ for flow mediated dilatation measurements taken on three separate days from the same individual was $6.9 \%$.

BMI was measured as body weight in $\mathrm{Kg}$ divided by the square of the height in metres.

\section{Protein carbonyl determination}

Plasma protein carbonyls represent the steady state rate of protein synthesis, oxidation and removal which can be influenced by nutrients that affect free radical formation and expression of clearance pathways [20]. Here carbonyls were analysed to provide insight into the systemic steady state of protein oxidation following almond intervention and were determined by ELISA as previously described by Carty et al[21].

\section{$\alpha$-tocopherol analysis}

Plasma aliquots $(300 \mu \mathrm{l})$ were thawed with addition of $300 \mu \mathrm{l}$ of ethanol (containing $80 \mu \mathrm{M} \alpha-$ tocopherol acetate as internal standard). Following hexane extraction in the presence of 2, 6-di-tert-butyl-4-methylphenol, the organic phase was evaporated to dryness, then reconstituted with $300 \mu$ l methanol[22]. Reverse phase chromatography (Phenomenex Gemini 5 micron C18 110A column) was used to separate $\alpha$-tocopherol levels in plasma. $\alpha$ - 
tocopherols were eluted using methanol at a flow rate of $1 \mathrm{ml} / \mathrm{min}$ with detection at $292 \mathrm{~nm}$. Between batch accuracy of analysis was $5.3 \%$.

\section{Plasma nitrite analysis}

Plasma nitrites were determined using a fluorimetric assay kit according to the manufacturer's instructions with modification to remove proteins (Cayman Chemical Company Cat. No. 780051).

\section{Statistical analysis}

Analyses were carried out with GraphPad Prism. The results are given as means \pm SDs unless otherwise noted. Changes over time were examined with repeated-measures analysis of variance. If a significant time effect $(P<0.05)$ was obtained, individual time points were compared by using the Tukey-Kramer adjustment. Correlations among variables were calculated by using Pearson's product-moment correlation coefficients. 


\section{RESULTS}

\section{Subjects}

The mean age of subjects recruited into group 1 was significantly higher than all other groups ( $p<0.001 ;$ Table 1 ). Consistent with the effects of ageing on metabolism, total plasma cholesterol levels were significantly higher in the healthy, middle-aged adult group $(181 \mathrm{mg} / \mathrm{dL})$ compared to the habitual diet group $(152 \mathrm{mg} / \mathrm{dL})$ and healthy, young group $(154 \mathrm{mg} / \mathrm{dL})$ at baseline $(p=0.03)$. The total plasma cholesterol and LDL cholesterol concentrations were similar in the healthy, middle-aged population to the younger, at risk group. However, HDL cholesterol concentration was significantly increased in the healthy middle-aged adult population $(58.0 \pm 10.75 \mathrm{mg} / \mathrm{dL})$ compared to all other groups (healthy younger: $49.85 \pm 9 \mathrm{mg} / \mathrm{dL}$; younger at risk: $47.44 \pm 7.50 \mathrm{mg} / \mathrm{dL}$; habitual diet group: $53.27 \pm 15.0 \mathrm{mg} / \mathrm{dL} ; \mathrm{p}<0.001)$. Plasma triacylglycerol concentrations were elevated significantly in the young, risk group $(138+31 \mathrm{mg} / \mathrm{dL})$ compared to other subjects enrolled into the study (healthy middle-aged: $124.00 \pm 28.50 \mathrm{mg} / \mathrm{dL}$; healthy younger: $119.70 \pm$ $20 \mathrm{mg} / \mathrm{dL}$; habitual diet group: $123 \pm 33.0 \mathrm{mg} / \mathrm{dL} ; \mathrm{p}<0.001$ ).

In order to identify any association between age and established cardiovascular risk factors in the total recruited population at baseline, correlation analysis was performed; significant correlations were observed between age with total cholesterol $(p=0.001)$, age with HDL cholesterol $(p<0.05)$ and age with diastolic BP $(p<0.001)$.

\section{Dietary intakes by subjects}

BMI, food composition analysis and calorie intake were recorded to inform any effects of almond intake on dietary habits and body weight. Dietary habits during the intervention were analysed using Dietplan 6 (Table 2). Prior to the study, total fat intake for the cohort was $\sim 30 \%$ of calories. During the intervention, total dietary fat was increased significantly to 
an estimated $36 \%$ of calories in the healthy, middle-aged group only $(p=0.003)$; this effect was reflected in an increase in MUFA and PUFA intakes. Dietary analysis of all intervention group diaries showed a significant increase in estimated MUFA intake $(p<0.02)$. After the intervention, there was a general trend for reduced saturated fat and cholesterol intake compared to the start of the study. BMI was elevated significantly over four weeks in the habitual diet (no almond control) and the young group, but neither the "at risk" group nor the healthy, middle-aged group showed any change in BMI with almond intake (data not shown).

Effects of almond supplementation on plasma protein oxidation, nitrite and $\alpha$-tocopherol Plasma $\alpha$-tocopherol corrected for LDL concentration was not different between groups at baseline and was increased significantly from $6.6 \pm 0.4 \mathrm{mmol} \alpha$-tocopherol $/ \mathrm{mol}$ LDL to $6.8 \pm 0.44 \mathrm{mmol} \alpha$-tocopherol/mol LDL after $50 \mathrm{~g} / \mathrm{d}$ almonds (mean+SEM). There was no correlation between plasma $\alpha$-tocopherol/LDL for any measure of vascular function.

Plasma nitrite and protein carbonyl concentrations were not different between any of the study groups and remained unchanged after intake of $50 \mathrm{~g} / \mathrm{d}$ almonds for 4 weeks (carbonyls; $2.9+0.17 \mathrm{nmol} / \mathrm{mg}$ at week 0 compared to $2.8+0.16 \mathrm{nmol} / \mathrm{mg}$ at week 4 and nitrite; 5.6+0.52 at week 0 compared with $5.8+0.55$ at week 4)

\section{Effect of almond intake on plasma cholesterol and triacylglycerol concentrations.}

Plasma cholesterol concentrations of subjects in all groups were measured to determine whether almond consumption had any effect on lipid distribution. Intervention with almonds had no significant effect on total plasma cholesterol concentrations in any group and the cholesterol concentration in the habitual diet group did not change over the period of study. 
Plasma triacylglycerol HDL-, and LDL-cholesterol concentrations remained unchanged after intake of $50 \mathrm{~g} / \mathrm{d}$ almonds for 4 weeks

Using two-way ANOVA, the between group triacylglycerol, total, LDL and HDL cholesterol concentrations remained significantly different after almond intervention.

\section{Effect of almond intake on blood pressure and vascular reactivity}

The diastolic BPs of subjects within the healthy middle-aged and healthy younger groups decreased significantly ( $-6 \%$ and $-12 \%$ respectively) after $50 \mathrm{~g}$ almonds per day for four weeks (Figure 1a; $P=0.015$ and 0.002 respectively). Diastolic BP remained unchanged in the young, at risk group after almonds and in the group that remained on their habitual diet.

In all intervention groups, systolic BP was decreased significantly following 50g almonds/day for 4 weeks (Figure $1 b ; p<0.01$, by $-6 \%$ within the healthy middle-aged, $-5 \%$ within the healthy young and $-4 \%$ in the young at risk group) but the control group who maintained their habitual diet showed no change in systolic BP. There was a significant difference in systolic BP between subject groups $(p<0.001)$ at baseline which remained after intervention. In a follow-up phase of the study ( 8 weeks on a habitual diet without almonds), we observed that systolic BP returned to pre-almond diet levels (data not shown).

Hyperemic reactive blood flow following vessel occlusion was investigated as a measure of the effect of the almond-enriched diet on vascular function and was analysed during the early morning to eliminate confounding by diurnal variation. There were no inter-group differences in flow mediated dilatation (FMD) at the start of the study, although older adults and young at risk subjects had lower median FMD. However, a significant increase in FMD was observed after $50 \mathrm{~g}$ almonds per day for four weeks in the young groups and a trend for increase was observed in the older adults with 12/15 showing an improvement in blood 
flow ( $p=0.03$; Figure 2). There was a trend for a reduction in blood flow in the subjects who maintained a habitual diet $(p<0.2)$. 


\section{Discussion}

In the present study we have shown that an almond enriched diet can reduce BP and improve vascular function but not lipid profiles in middle-aged, healthy subjects and younger subjects with and without risk factors for CVD. Despite the elevation of plasma $\alpha-$ tocopherol following almond intervention, no other parameters measured here relating to oxidation (nitrite formation or protein carbonyls) were influenced by the dietary change. This is consistent with previous supplementation studies that have attempted unsuccessfully to address cardiovascular risk with $\alpha$-tocopherol supplementation based on a hypothesis that vitamin E is exerting an antioxidant effect[23]. Nevertheless, the data reported here confirm the suggestion that $\alpha$-tocopherol is acting hermetically e.g. through promoting autophagic clearance of intracellular fibrotic proteins [11] or is a correlate for nutrients which may improve cardiovascular health, such as MUFA which are antiinflammatory in vitro and in vivo [17,24]. Epidemiological evidence suggests that consumption of a diet enriched in MUFA and tocopherols including nuts, reduces BP and lipid levels [6,25-27]. Indeed, frequent nut consumption of between 1-4 times per week has been reported to reduce risk of CVD mortality by 25\% [28].

Muscle relaxation in response to sympathetic activity can be measured as FMD [29]. FMD is influenced by the bioavailability of nitric oxide which may be consumed by reaction with superoxide anion radicals that are produced during inflammation. Almonds are enriched in arginine, a rate-limiting substrate for endothelial nitric oxide synthesis and in vitamin $E$, a free radical scavenger and together are predicted to increase bioavailable nitric oxide and FMD. FMD, which has been used as predictive tool for future CVD events [30], was lower in younger, at risk subjects when compared to subjects in the other groups. FMD was improved significantly in the supplemented cohort after 50g almond per day, with the 
greatest benefit being observed in the at risk group. Nitrite levels were unaffected, however.

Age-dependent vascular stiffness may also be dependent on reduced baroreceptor reflex activity, typically seen as postural hypotension in older adults [31]. The mechanisms of baroreceptor control by nutrients are not well understood, however, recent reports have suggested that redox imbalances induces hypertensive and baroreflex responses in rates and that tocopherol delivered pre-natally can modulate vascular responses in hypoxia $[32,33]$. In addition, lipid abnormalities may mediate this effect; hyperlipidemia in obese hypertensive individuals has been attributed to impairment of the baroreceptor reflex leading to increased BP [34]. In pre-diabetes subjects with insulin resistance, no improvement of systolic BP was noted after almond consumption [16,35].. In the present study, systolic BP was decreased significantly in all intervention groups but not the control group who maintained their habitual diet and did not consume almonds. Diastolic BP was significantly reduced with almond supplementation in healthy subjects only, irrespective of age. Systolic BP reduction has been suggested as a more important target for reduction in older adults to reduce cardiovascular events[36].

The relationship between $\mathrm{BP}$ and age remained significant in this cohort after almond intake, probably reflecting the multiple facets of vascular elasticity that undergo irreversible change during ageing e.g. oxidation or glycation of matrix proteins [37].

In the present study, the difference in cholesterol concentrations between middle-aged and young subjects are not mitigated by following an almond-enriched diet for 4 weeks, and the age-associated correlation with cholesterol and LDL-cholesterol concentration remains significant after a four week intervention with $50 \mathrm{~g}$ almonds per day. This supports the premise that ageing-induced changes in metabolism are responsible for increased plasma 
lipids, and that while changing to a vitamin E and MUFA-enriched diet can improve the elevated lipid profile, the age-effect remains.

We have demonstrated here that dietary almond intake improved markers of vascular function. Despite an additional 300kcal to the dietary energy intake, no significant intake in calories was reported in the food diaries for any group nor was there any significant change in $\mathrm{BMI}$ in the intervention groups suggesting energy compensation by subjects; this compensation effect has been reported in previous studies with almond snacks [38]. It has been reported previously that nut intake increases satiety, which may explain the reduction in calories consumed from non-almond foods [39].

In summary, the higher BPs and lipid concentrations observed in men with increasing age is still evident after an almond enriched diet, nevertheless, similar to younger adults, middleaged adults do benefit from increased almond intake $(50 \mathrm{~g} / \mathrm{d}$; 4 weeks) with improvements in vascular function that are expected to reduce risk of CVD.

In an ageing population with substantial CVD morbidity and mortality, interventions that decrease the incidence and/or severity of CVD in middle-aged adults are expected to have a major impact on global health and related health care costs. 


\section{Acknowledgments}

Financial support from the Food Standards Agency in the form of a Postgraduate Student Scholarship to Dr Khujesta Choudhury is gratefully acknowedged. Almonds were kindly provided by the Almond Board, California, USA. 


\section{References}

[1]. Cruzen C, Colman R, J. . Effects of Caloric Restriction on Cardiovascular Aging in Non-human Primates and Humans. Clinics in Geriatric Medicine 2009;25(4):733-743.

[2]. Rajeshwar K, Kaul S, Al-Hazzani A, Babu MS, Balakrishna N, Sharma V, Jyothy A, Munshi A. C-reactive protein and nitric oxide levels in ischemic stroke and its subtypes: correlation with clinical outcome. Inflammation 2012;35(3):978-84.

[3]. Chobanian AV, Bakris GL, Black HR, Cushman WC, Green LA, Izzo JL, Jr, Jones DW, Materson BJ, Oparil S, Wright JT, Jr and others. The Seventh Report of the Joint National Committee on Prevention, Detection, Evaluation, and Treatment of High Blood Pressure: The JNC 7 Report. JAMA 2003;289(19):2560-2571.

[4]. Patel RS, Al Mheid I, Morris AA, Ahmed Y, Kavtaradze N, Ali S, Dabhadkar K, Brigham K, Hooper WC, Alexander RW and others. Oxidative stress is associated with impaired arterial elasticity. Atherosclerosis 2011;218(1):90-5.

[5]. Fleenor BS, Sindler AL, Eng JS, Nair DP, Dodson RB, Seals DR. Sodium nitrite destiffening of large elastic arteries with aging: role of normalization of advanced glycation end-products. Exp Gerontol 2012;47(8):588-94.

[6]. Aravanis C, Corcondilas A, Dontas A, Lekos D, Keys A. Coronary heart disease in seven countries. IX. The Greek islands of Crete and Corfu. Circulation 1970;41(4 Suppl):13.

[7]. Bjelakovic G, Nikolova D, Gluud LL, Simonetti RG, Gluud C. Antioxidant supplements for prevention of mortality in healthy participants and patients with various diseases. Cochrane Database Syst Rev 2012;3:CD007176.

[8]. Forman HJ, Davies KJ, Ursini F. How do nutritional antioxidants really work: Nucleophilic tone and para-hormesis versus free radical scavenging in vivo. Free Radic Biol Med 2014;66:24-35.

[9]. Rattan SI. Targeting the age-related occurrence, removal, and accumulation of molecular damage by hormesis. Ann N Y Acad Sci 2010;1197:28-32.

[10]. Karim MR, Fujimura S, Kadowaki M. Vitamin E as a novel enhancer of macroautophagy in rat hepatocytes and H4-II-E cells. Biochem Biophys Res Commun 2010;394(4):981-7.

[11]. LaRocca TJ, Gioscia-Ryan RA, Hearon CM, Jr., Seals DR. The autophagy enhancer spermidine reverses arterial aging. Mech Ageing Dev 2013;134(7-8):314-20.

[12]. Hu F, Stampfer M, Manson J, Rimm E, Colditz G, Rosner B, Hennekens C, Willett W. Dietary fat intake and the risk of coronary heart disease in women. N Engl J Med 1997;337:1491-1499.

[13]. Albert CM, Gaziano JM, Willett WC, Manson JE. Nut Consumption and Decreased Risk of Sudden Cardiac Death in the Physicians' Health Study. Arch Intern Med 2002;162(12):1382-1387.

[14]. Barreira JCM, Ferreira ICFR, Oliveira MBPP, Pereira JA. Antioxidant activity and bioactive compounds of ten Portuguese regional and commercial almond cultivars. Food and Chemical Toxicology 2008;46(6):2230-2235.

[15]. Phung OJ, Makanji SS, White CM, Craig IC. Almonds Have a Neutral Effect on Serum Lipid Profiles: A Meta-Analysis of Randomized Trials. Journal of the American Dietetic Association 2009;109(5):865-873.

[16]. Wien M, Bleich D, Raghuwanshi M, Gould-Forgerite S, Gomes J, Monahan-Couch L, Oda K. Almond Consumption and Cardiovascular Risk Factors in Adults with Prediabetes. J Am Coll Nutr 2010;29(3):189-197.

[17]. Rajaram S, Connell K, Sabaté J. Effect of almond-enriched high-monounsaturated fat diet on selected markers of inflammation: a randomised, controlled, crossover study. Br J Nutr 2010;103(6):907-913. 
[18]. Schouw YTvd, Graaf Yvd, Steyerberg EW, Eijkemans MJC, Banga JD. Age at menopause as a risk factor for cardiovascular mortality. The Lancet 1996;347(9003):714-718.

[19]. Ginsberg HN, Kris-Etherton P, Dennis B, Elmer PJ, Ershow A, Lefevre M, Pearson T, Roheim P, Ramakrishnan R, Reed R and others. Effects of Reducing Dietary Saturated Fatty Acids on Plasma Lipids and Lipoproteins in Healthy Subjects : The Delta Study, Protocol 1. Arterioscler Thromb Vasc Biol 1998;18(3):441-449.

[20]. Griffiths HR, Dias IHK, Willetts RS, Devitt A. Redox Regulation of Protein Damage in Plasma. Redox Biology (0).

[21]. Carty JL, Bevan R, Waller H, Mistry N, Cooke M, Lunec J, Griffiths HR. The effects of vitamin $\mathrm{C}$ supplementation on protein oxidation in healthy volunteers. Biochemical and Biophysical Research Communications 2000;273(2):729-735.

[22]. Rizzo C, Dionisi-Vici, C., D’Ippoliti, M., Fina, F., Sabetta, G., and Federici, G.,. A simple and rapid HPLC method for simultaneous determination of plasma 7dehydrocholesterol and vitamin E: its application in Smith-Lemli-Opitz patients. Clinica Chemica Acta 2000;291:97-102.

[23]. McQueen MJ, Lonn, E., Gerstein, H. C., Bosch, J., Yusuf, S., . The HOPE (Heart Outcomes Prevention Evaluation) Study and its consequences. . Scand J Clin Lab Invest Suppl 2005;240:143-56.

[24]. Gao D, Pararasa C, Dunston CR, Bailey CJ, Griffiths HR. Palmitate promotes monocyte atherogenicity via de novo ceramide synthesis. Free Radic Biol Med 2012;53(4):796-806.

[25]. Einarsson K, Nilsell K, Leijd B, Angelin B. Influence of Age on Secretion of Cholesterol and Synthesis of Bile Acids by the Liver. New England Journal of Medicine 1985;313(5):277-282.

[26]. Hu FB, Stampfer MJ, Manson JE, Rimm EB, Colditz GA, Rosner BA, Speizer FE, Hennekens $\mathrm{CH}$, Willett WC. Frequent nut consumption and risk of coronary heart disease in women: prospective cohort study. Bmj 1998;317(7169):1341-5.

[27]. Kris-Etherton PM, Zhao G, Binkoski AE, Coval SM, Etherton TD. The effects of nuts on coronary heart disease risk. Nutr Rev 2001;59(4):103-11.

[28]. Dreher ML, Maher CV, Kearney P. The traditional and emerging role of nuts in healthful diets. Nutr Rev 1996;54(8):241-5.

[29]. Hijmering ML, Stroes ES, Olijhoek J, Hutten BA, Blankestijn PJ, Rabelink TJ. Sympathetic activation markedly reduces endothelium-dependent, flow-mediated vasodilation. J Am Coll Cardiol 2002;39(4):683-8.

[30]. Gokce N, Keaney JF, Hunter LM, Watkins MT, Nedeljkovic ZS, Menzoian JO, Vita JA. Predictive value of noninvasivelydetermined endothelial dysfunction for longterm cardiovascular events inpatients with peripheral vascular disease. Journal of the American College of Cardiology 2003;41(10):1769-1775.

[31]. James MA, Potter JF. Orthostatic blood pressure changes and arterial baroreflex sensitivity in elderly subjects. Age and Ageing 1999;28(6):522-530.

[32]. El-Mas MM, Mohy El-Din MM, Helmy MM, Omar AG. Redox imbalances incite the hypertensive, baroreflex, and autonomic effects of cyclosporine in rats. Eur J Pharmacol 2012;694(1-3):82-8.

[33]. Wu YC, Wang YJ, Tseng GF. Ascorbic acid and alpha-tocopherol supplement starting prenatally enhances the resistance of nucleus tractus solitarius neurons to hypobaric hypoxic challenge. Brain Struct Funct 2011;216(2):105-22.

[34]. Gadegbeku CA, Dhandayuthapani A, Sadler ZE, Egan BM. Raising lipids acutely reduces baroreflex sensitivity. Am J Hypertens 2002;15(6):479-85. 
[35]. Jenkins DJ, Kendall CW, Marchie A, Parker TL, Connelly PW, Qian W, Haight JS, Faulkner D, Vidgen E, Lapsley KG and others. Dose response of almonds on coronary heart disease risk factors: blood lipids, oxidized low-density lipoproteins, lipoprotein(a), homocysteine, and pulmonary nitric oxide: a randomized, controlled, crossover trial. Circulation 2002;106(11):1327-32.

[36]. Izzo JL, Jr., Levy D, Black HR. Clinical Advisory Statement. Importance of systolic blood pressure in older Americans. Hypertension 2000;35(5):1021-4.

[37]. Pugh KG, Wei JY. Clinical Implications of Physiological Changes in the Aging Heart*. Drugs \& Aging 2001;18(4):263-276.

[38]. Zaveri S, Drummond S. The effect of including a conventional snack (cereal bar) and a nonconventional snack (almonds) on hunger, eating frequency, dietary intake and body weight. Journal of Human Nutrition and Dietetics 2009;22(5):461-468.

[39]. Wien MA, Sabate JM, Ikle DN, Cole SE, Kandeel FR. Almonds vs complex carbohydrates in a weight reduction program. Int J Obes Relat Metab Disord 2003;27(11):1365-1372. 


\section{Tables}

Table 1 -Subject characteristics classified by intervention group

\begin{tabular}{|c|c|c|c|c|c|}
\hline & $\begin{array}{l}\text { Healthy middle- } \\
\text { aged }\end{array}$ & Healthy young & Young at risk & Control & $P$ value \\
\hline Age (years) & $56.07( \pm 5.77)$ & $22.14(+2.88)^{*}$ & $27.27(+5.04)^{*}$ & $23.00(+5.87)^{*}$ & $\begin{array}{l}* \mathrm{P}<0.001 \mathrm{v} \\
\text { healthy, } \\
\text { middle-aged }\end{array}$ \\
\hline BMI & $25.37 \pm 4.041$ & $19.99 \pm 1.595 *+$ & $26.34+4.321$ & $22.20 \pm 2.260+$ & $\begin{array}{l}{ }^{*} \mathrm{p}<0.05 \mathrm{v} \\
\text { healthy } \\
\text { middle-aged } \\
+\mathrm{v} \text { risk }\end{array}$ \\
\hline $\begin{array}{l}\text { Systolic blood } \\
\text { pressure } \\
(\mathrm{mmHg})\end{array}$ & $134.3+23.09$ & $119.6+12.51$ & $127.4+6.967$ & $119.7+11.50$ & NS, $p>0.05$ \\
\hline $\begin{array}{l}\text { Diastolic } \\
\text { blood } \\
\text { pressure } \\
(\mathrm{mmHg}) \\
\end{array}$ & $84.7+9.8$ & $73.3+7$ & $79.1+8.8$ & $68.8+9.0$ & $N S, p>0.05$ \\
\hline $\begin{array}{l}\text { Cholesterol } \\
(\mathrm{mg} / \mathrm{dL})\end{array}$ & $181+25.1$ & $154+28.57^{*}$ & $181+44.4$ & $152+28.6^{*}$ & $\begin{array}{l}* \mathrm{P}<0.05 \mathrm{v} \\
\text { healthy } \\
\text { middle-aged }\end{array}$ \\
\hline $\mathrm{LDL}(\mathrm{mg} / \mathrm{dL})$ & $116.10+30.45$ & $93.47+24.60 *+$ & $118.70+40.54$ & $87.92+25.70 *+$ & $\begin{array}{l}* \mathrm{P}<0.001 \mathrm{v} \\
\text { healthy } \\
\text { middle-aged } \\
+\mathrm{v} \text { risk }\end{array}$ \\
\hline $\mathrm{HDL}(\mathrm{mg} / \mathrm{dL})$ & $58.0+10.75+$ & $49.85+9.0 *$ & $47.44+7.50 *$ & $53.27+15.0 *+$ & $\begin{array}{l}* \mathrm{P}<0.001 \mathrm{v} \\
\text { healthy } \\
\text { middle-aged } \\
+\mathrm{v} \text { risk }\end{array}$ \\
\hline $\begin{array}{l}\text { Triacylglycerol } \\
(\mathrm{mg} / \mathrm{dL})\end{array}$ & $124.00+28.50+$ & $119.70+20.00 *+$ & $138+31^{*}$ & $123+33.00+$ & $\begin{array}{l}* \mathrm{P}<0.001 \mathrm{v} \\
\text { healthy } \\
\text { middle-aged } \\
+\mathrm{v} \text { risk }\end{array}$ \\
\hline
\end{tabular}

V = compared with

NS = not significant 
Table 2 - Dietary habits during the intervention were examined using self-reporting 3-day diet diaries

\begin{tabular}{|c|c|c|c|c|c|}
\hline $\begin{array}{l}\text { Food diary } \\
\text { analysis }\end{array}$ & intervention & $\begin{array}{l}\text { Healthy } \\
\text { middle- } \\
\text { aged }\end{array}$ & $\begin{array}{l}\text { Healthy } \\
\text { young }\end{array}$ & Young at risk & control \\
\hline \multirow{3}{*}{$\begin{array}{l}\text { Total dietary } \\
\text { fat intake }(\mathrm{g} / \mathrm{d})\end{array}$} & Og almonds & $75.0+6.0$ & $77.3+9.8$ & $75.5+11.5$ & $79.7+9.8$ \\
\hline & $\begin{array}{l}\text { habitual } \\
\text { weeks }\end{array}$ & - & - & - & $74.6+11.3$ \\
\hline & $50 \mathrm{~g} / \mathrm{d}$ 4weeks & $96.4+4.9 * *$ & $76.7+6.5$ & $74.6+7.7$ & - \\
\hline \multirow{3}{*}{$\begin{array}{l}\text { MUFA } \\
\text { (g/d) }\end{array}$} & Og almonds & $21.3+2.1$ & $26.3+4.7$ & $24.6+4$ & $26.1+4.7$ \\
\hline & $\begin{array}{l}\text { habitual } 4 \\
\text { weeks }\end{array}$ & - & - & - & $25.8+4.5$ \\
\hline & $50 \mathrm{~g} / \mathrm{d}$ 4weeks & $\begin{array}{r}39.6+ \\
1.7 * * *\end{array}$ & $\begin{array}{l}39.8+ \\
2.6 * *\end{array}$ & $33.3+2.5 *$ & - \\
\hline \multirow{3}{*}{$\begin{array}{l}\text { PUFA } \\
\text { (g/d) }\end{array}$} & Og almonds & $11.5+1.2$ & $17.6+4$ & $11.4+1.9$ & $13.2+1.2$ \\
\hline & $\begin{array}{l}\text { habitual } \\
\text { weeks }\end{array}$ & - & - & - & $10.1+1.0 *$ \\
\hline & $50 \mathrm{~g} / \mathrm{d}$ 4weeks & $17.3+1^{* *}$ & $16.9+0.6$ & $13.3+1.3$ & - \\
\hline \multirow[t]{3}{*}{$\begin{array}{l}\text { Calorie intake } \\
\text { (kcal/d) }\end{array}$} & Og almonds & $2050+107$ & $2211+265$ & $2128+341$ & $2131+237$ \\
\hline & $\begin{array}{ll}\text { habitual } & 4 \\
\text { weeks } & \end{array}$ & - & - & - & $1941+237$ \\
\hline & $50 \mathrm{~g} / \mathrm{d} 4$ weeks & $\begin{array}{c}2268+ \\
143^{*}\end{array}$ & $2583+129$ & 194439 & - \\
\hline
\end{tabular}

* $\quad \mathrm{P}<0.05$

** $\quad \mathrm{P}<0.01$

$P<0.001$ 
middle-aged, healthy
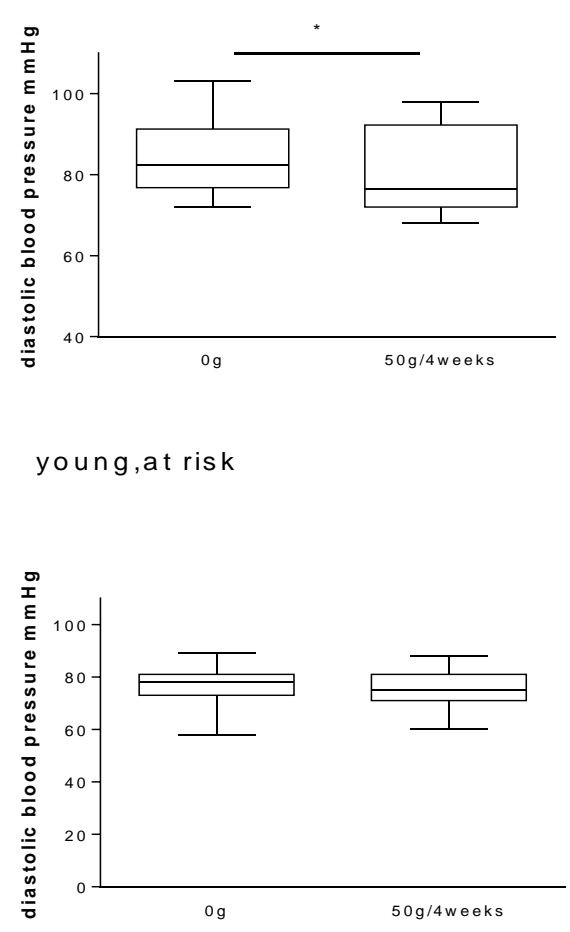

young, healthy

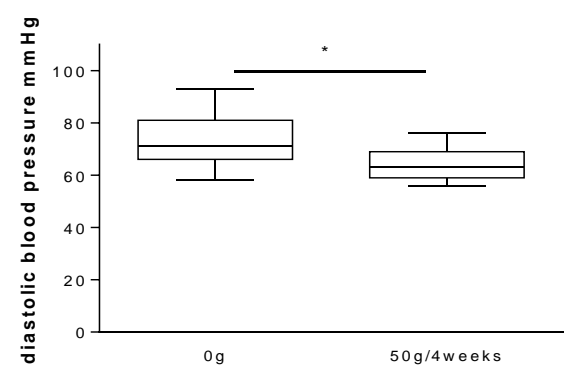

control

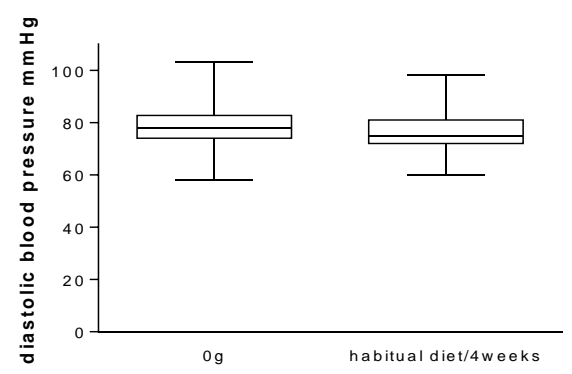

Figure ia

24 
m iddle-aged, health y
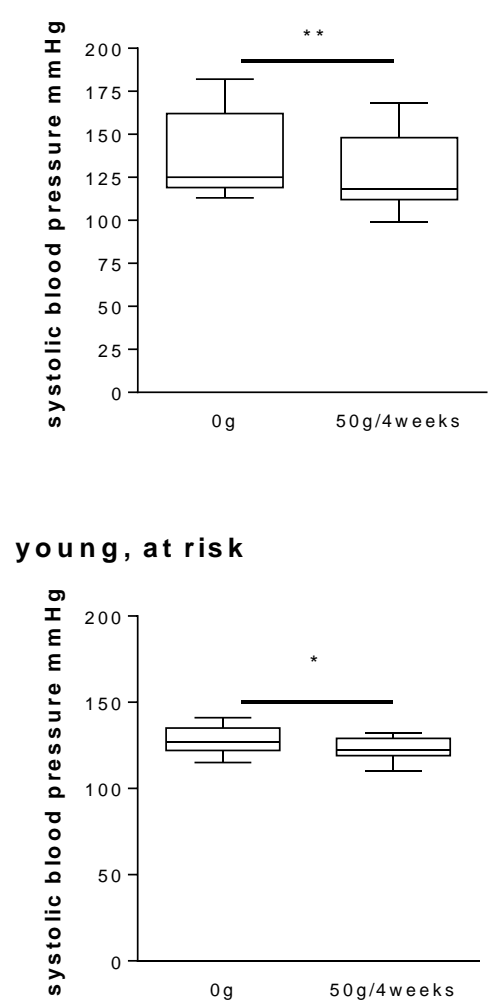

young, healthy

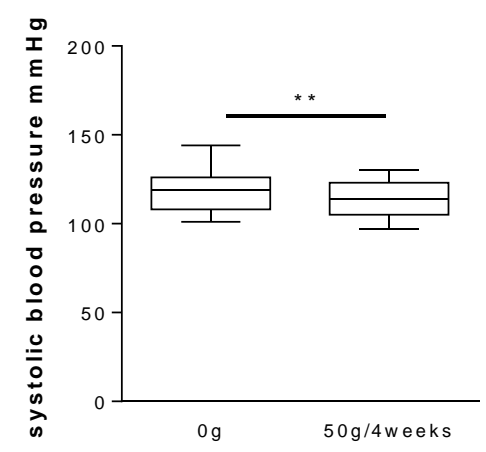

control

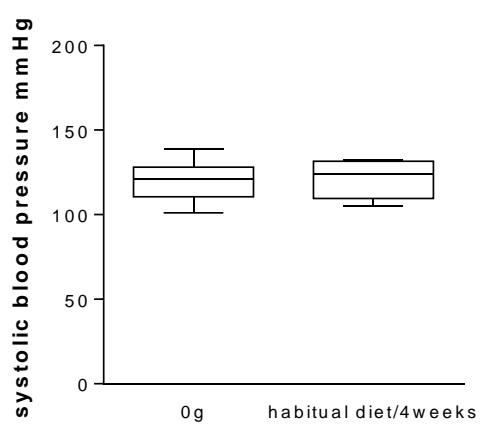

Figure $1 b$ 


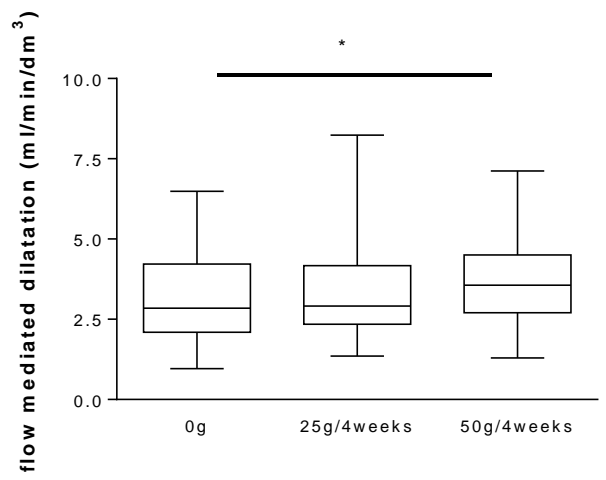

Figure 2 


\section{Figure Legends}

Figure 1. Blood pressure ( $a$ - diastolic; $b$ - systolic) was determined by venous plethysmography in each subject at baseline and following four weeks of almond intervention with $50 \mathrm{~g}$ almonds/day (d). Data are expressed as box and whisker plots with the box showing median and $75 \%$ confidence intervals and data range shown as whiskers where $*$ represents $p<0.05$ and $* *$ represents $p<0.01$.

Figure 2. Flow mediated dilatation was measured in each subject at baseline, following four weeks $25 \mathrm{~g}$ almonds/day (d) and following four weeks of almond intervention (50g/d). Data are expressed as box and whisker plots with the box showing median and $75 \%$ confidence intervals and data range shown as whiskers where * represents $p<0.05$ and $* *$ represents $p<0.01$. 